\title{
Age-related peculiarities of changes in functional state of a person in the recreation areas
}

\author{
Elena Malysheva ${ }^{1 *}$, Elena Skripnikova ${ }^{1}$, and Tatiana Logina ${ }^{1}$ \\ ${ }^{1}$ Tambov State University named after G.R. Derzhavin, 392000, Tambov, Russia
}

\begin{abstract}
The article is devoted to the study of physiological effects of staying in the park areas in people of different ages. The study involved 20 students aged 18-20 years; 20 schoolchildren aged $14-15$ years; 11 elderly people aged 69-76 years. We recorded tidal volume and respiratory rate, took blood pressure and counted heart rate, calculated hemodynamic parameters. We analyzed the parameters of attention, determined the capacity of short-term auditory and visual memory. All studied parameters were recorded before and after a walk in the park. While people spend time in the open air in recreation areas, the positive dynamics in cardiorespiratory system is observed: a decrease in blood pressure and heart rate, but maximal pulmonary ventilation increases. Also, we noticed that the level of state anxiety has reduced. We have discovered that the influence of recreation area environment on the functional state of test subjects depends on their age The magnitude of the changes depends on the deviation of the initial parameters from the normal values. The most positive values are observed in people with maximum deviation from the norm. The practical significance of the study is to expand the range of drug-free methods to enhance functions of cardiovascular, respiratory systems and the brain in elderly people with the help of sensory environment of recreation areas.
\end{abstract}

\section{Introduction}

City and urbanization are the future of human civilization. In the history of ancient states and modern developed countries, the growth of the power of society invariably comes against the background of the process of urbanization. At the same time, the city is the most uncomfortable environment for humans as a biological system. The logical outcome of an increase in the proportion of the urban population and its density is an increase in the strength and tension of social stress, negative consequences for homeostatic mechanisms of people.Urban development leads to a progressive environmental degradation, leading to massive and chronic people health decrease. It is shown that loud and aggressive sounds, monotonous urbanized environment have a negative impact on the

\footnotetext{
${ }^{*}$ Corresponding author: birucovatgu@ mail.ru
} 
internal rhythms of the body and negatively affect the work of organs. There is some evidence of a negative impact of city noise on learning and memory functions [1]. It should be noted that railway noise has a more negative impact on learning and memory acquisition, increases anxiety [2].

For hundreds of years, they have been trying to neutralize the harmful effects of urban conditions on health by simulating the natural environment in residential areas. The most common method for achieving this goal is landscape gardening, which has a beneficial effect on the arrangement of park zones. Since the time immemorial, people have been in close interaction with nature. They have been surrounded by plants, natural landscapes and a variety of sounds. There have been the singing of birds, the murmur of a stream, the rustle of brushwood and leaves. All these sounds surrounded a person and informed him about the external environment. Based on innate and acquired experience, a person perceives sounds in different ways. For example, a high scream was an alarm. At the same time, there were soothing sounds - the noise of leaves, the whistling of the wind.

It is known that exposure to natural sounds and visualization of images of nature evokes a feeling of relaxation; however, there are few studies in the scientific literature devoted to studying the physiological effects of staying in a natural environment or park areas. Thus, the beneficial effect of nature sounds on hemodynamic parameters in patients with traumatic coma [3], in patients in intensive care units has been shown[4, 5]. The image and sounds of the forest in healthy people cause a decrease in blood pressure, heart rate, and reduce anxiety $[6,7]$. In other studies, the sounds of nature do not affect blood pressure, but change the parameters of the respiratory system [8]. Attention restoration theory argues that naturally-occurring stimuli can restore directed attention, reducing requirements for the endogenous attention system. In a study by Van Hedger S. et al. (2019), people who listened to the sounds of nature were observed significant improvements in cognitive functions compared to participants who listened to the sounds of the city [9].

The aim of this research was to study the physiological effects of staying in park areas in people of different ages.

\section{Material and Methods}

The study involved 20 students aged 18-20 years; 20 schoolchildren aged 14-15 years; 11 elderly people aged 69-76 years.

The values of respiratory rate (RR), respiratory minute volume (RMV), maximal pulmonary ventilation(MPV) were recorded with the help of a spirograph.

To analyze the parameters of attention, Anfimov's table technique was used. Mental capacity mainly depends on the intensity of functioning of sensory systems that perceive information, on the state of attention, memory, thinking, and the expressiveness of emotions. Mental capacity parameters are used for integral characteristics of the functional state of the organism.

To test auditory memory, 40 words without meaning were read out, divided into 4 series. It took 20 seconds to repeat words of each series. The subjects' task was to remember and record the words he heard.

Blood pressure and heart rate were taken. The following parameters were used to characterize hemodynamics: pulse pressure (PP); systolic volume (SV); minute volume / cardiac output (MV); vegetative index of Kerdo (KI) is defined by Davydov formula:

$$
K I=(1-D P / H R) * 100 \%
$$

where DP-diastolic pressure, HR-heart rate. 
This parameter allows us to predict the direction of hemodynamics towards hypertension or hypotension in people. The condition of the organism is considered normal if the KI has a positive value, and the higher this value, the more stable and better the condition of the organism.

All studied parameters were recorded at the beginning of the walk, after a walk in the city center and after a walk in the park.

Statistical processing of the results was carried out using the program «Statistica 10.0».

\section{Results and discussion}

The analysis of the results showed that there are slight improvements related to initial values in the group of young people after a walk in the park than before a walk. There are fewer mistakes, the number of selected symbols, the capacity of visual memory, the speed of information processing increase, but the attention span decreases (table1).

Table 1. Trends in parameters of mental capacity after a walk in the park in young people.

\begin{tabular}{|c|c|c|c|}
\hline \multirow{2}{*}{ Parameters } & Initial value & After walk & \multirow{2}{*}{$\Delta \%$} \\
\cline { 2 - 3 } & $\mathrm{M} \pm \delta$ & $\mathrm{M} \pm \delta$ & 8,93 \\
\hline Total amount of symbols & $403,23 \pm 90,65$ & $439,24 \pm 97,81$ & 35,79 \\
\hline Chosen symbols & $40,76 \pm 10,27$ & $55,35 \pm 12,52$ & 4,22 \\
\hline Auditory memory & $6,88 \pm 1,10$ & $7,17 \pm 1,50$ & $-66,43$ \\
\hline Mistakes & $1,40 \pm 1,70$ & $0,47 \pm 0,87$ & 2,59 \\
\hline Accuracy coefficient & $0,967 \pm 0,033$ & $0,992 \pm 0,01$ & 5,08 \\
\hline $\begin{array}{c}\text { Coefficientof intellectual } \\
\text { efficiency }\end{array}$ & $389,05 \pm 84,55$ & $408,82 \pm 116,45$ & 11,87 \\
\hline $\begin{array}{c}\text { Capacity of visual } \\
\text { memory }\end{array}$ & $239,35 \pm 53,8$ & $267,75 \pm 58,05$ & 12,21 \\
\hline $\begin{array}{c}\text { Information processing } \\
\text { speed }\end{array}$ & $3,85 \pm 0,92$ & $4,32 \pm 0,96$ & $-19,18$ \\
\hline Attention span & $9,7 \pm 0,72$ & $7,84 \pm 0,87$ & \\
\hline
\end{tabular}

The hemodynamic parameters in young people before walk were within the norm, so they did not change much after a walk (table.2).

Table2. Trends in hemodynamic parameters of young people after walk.

\begin{tabular}{|l|c|c|c|}
\hline \multicolumn{1}{|c|}{ Parameters } & Initial value & After walk & \multirow{2}{*}{$\Delta \%$} \\
\cline { 2 - 3 } & $\mathrm{M} \pm \sigma$ & $\mathrm{M} \pm \sigma$ & $-4,92$ \\
\hline $\mathrm{SBP}, \mathrm{mm} \mathrm{Hg}$ & $115,54 \pm 16,93$ & $109,86 \pm 15,74$ & $-4,15$ \\
\hline $\mathrm{DBP}, \mathrm{mm} \mathrm{Hg}$ & $63,64 \pm 8,445$ & $61 \pm 7,96$ & $-4,46$ \\
\hline $\mathrm{PP}, \mathrm{mm} \mathrm{Hg}$ & $51,286 \pm 11,78$ & $49 \pm 11,77$ & $-6,41$ \\
\hline $\mathrm{HR}, \mathrm{b} / \mathrm{min}$ & $85,78 \pm 13,45$ & $80,28 \pm 16,92$ & 0,42 \\
\hline $\mathrm{SV}, \mathrm{ml}$ & $71,33 \pm 6,64$ & $71,63 \pm 6,88$ & $-6,45$ \\
\hline $\mathrm{MV}, \mathrm{ml}$ & $6158,55 \pm 1337,85$ & $5761,19 \pm 1418,18$ & $-10,28$ \\
\hline $\mathrm{KI}, \%$ & $24,42 \pm 14,25$ & $21,91 \pm 14,34$ & \\
\hline
\end{tabular}

All tested young people initially had a low level of state anxiety and an average level of trait anxiety. Parameters of the respiratory system were within normal limits. After a walk 
in the park, the level of state anxiety decreased, but the respiratory rate, the respiratory minute volume, the maximal pulmonary ventilation increased (table.3).

Table3. The influence of a walk in the park on the parameters of the respiratory system and the level of anxiety.

\begin{tabular}{|c|c|c|c|}
\hline \multirow{2}{*}{ Parameters } & Before walk & After walk & \multirow{2}{*}{$\Delta \%$} \\
\cline { 2 - 3 } & $\mathrm{M} \pm 6$ & $\mathrm{M} \pm 6$ & \\
\hline State anxiety & $12,75 \pm 2,49$ & $10,25 \pm 1,38$ & $-19,6$ \\
\hline Trait anxiety & $36,50 \pm 6,21$ & $35,00 \pm 6,3$ & -4 \\
\hline RR & $20,30 \pm 6,4$ & $26,60 \pm 14,23$ & 31 \\
\hline RMV, л/мин & $11,21 \pm 5,2$ & $15,20 \pm 7,96$ & 36 \\
\hline MPV, л/мин & $53,38 \pm 8,66$ & $65,20 \pm 8,46$ & $22,14^{*}$ \\
\hline
\end{tabular}

Note: $*$ - significance of differences in $p<0,05$.

In elderly people after staying in a park area, mental capacity slightly improves, which shows itself in an increase in intellectual efficiency, accuracy in completing tasks, as well as an improved visual and auditory memory, though attention span decreases(table 4).

Table4. Trends in parameters of mental capacity after a walk in the park in elderly people.

\begin{tabular}{|c|c|c|c|}
\hline \multirow{2}{*}{ Parameters } & Initial value & After walk & \multirow{2}{*}{$\Delta \%$} \\
\cline { 2 - 3 } & $\mathrm{M} \pm \delta$ & $\mathrm{M} \pm \delta$ & 17,6 \\
\hline Total amount of symbols & $352,02 \pm 98,65$ & $414,23 \pm 77,11$ & $29,44^{*}$ \\
\hline Chosen symbols & $42,76 \pm 8,97$ & $55,35 \pm 8,52$ & 28,98 \\
\hline Auditory memory & $6,59 \pm 1,10$ & $8,50 \pm 1,50$ & $-64,47^{*}$ \\
\hline Mistakes & $1,52 \pm 0,53$ & $0,54 \pm 0,37$ & $3,99^{*}$ \\
\hline Accuracy coefficient & $0,952 \pm 0,033$ & $0,990 \pm 0,01$ & 9,23 \\
\hline $\begin{array}{c}\text { Coefficientof intellectual } \\
\text { efficiency }\end{array}$ & $365,19 \pm 74,55$ & $398,88 \pm 96,45$ & 18,37 \\
\hline $\begin{array}{c}\text { Capacity of visual } \\
\text { memory }\end{array}$ & $214,36 \pm 59,79$ & $253,75 \pm 48,14$ & 14,01 \\
\hline $\begin{array}{c}\text { Information processing } \\
\text { speed }\end{array}$ & $3,64 \pm 0,92$ & $4,15 \pm 0,96$ & $-20,52^{*}$ \\
\hline Attention span & $9,6 \pm 0,72$ & $7,63 \pm 0,93$ & \\
\hline
\end{tabular}

Note: * - significance of differences in $p<0,05$.

A walk in the park had a positive effect on hemodynamic parameters in the elderly people. Their systolic and diastolic blood pressure significantly decreased, their heart rate slightly decreased. There is also an increase in the Kerdo index from negative values, which indicates an improvement in the balance of sympathetic and parasympathetic effects on heart (table.5).

Table5.Trends in hemodynamic parameters of elderly people after walk.

\begin{tabular}{|c|c|c|c|}
\hline \multirow{2}{*}{ Parameters } & Initial value & After walk & \multirow{2}{*}{$\Delta \%$} \\
\cline { 2 - 3 } & $\mathrm{M} \pm \sigma$ & $\mathrm{M} \pm \sigma$ & \\
\hline $\mathrm{SBP}, \mathrm{mm} \mathrm{Hg}$ & $145,13 \pm 21,02$ & $125,63 \pm 18,22$ & $-13,43^{*}$ \\
\hline $\mathrm{DBP}, \mathrm{mm} \mathrm{Hg}$ & $93,55 \pm 14,23$ & $74,99 \pm 11,32$ & $-19,84^{*}$ \\
\hline PP, mm Hg & $49,65 \pm 15,37$ & $48,77 \pm 10,67$ & $-1,77$ \\
\hline
\end{tabular}




\begin{tabular}{|c|c|c|c|}
\hline $\mathrm{HR}, \mathrm{b} / \mathrm{min}$ & $78,54 \pm 7,12$ & $75,22 \pm 5,63$ & $-4,22$ \\
\hline $\mathrm{SV}, \mathrm{ml}$ & $66,29 \pm 11,67$ & $68,20 \pm 9,86$ & 2,88 \\
\hline $\mathrm{MV}, \mathrm{ml}$ & $5246,23 \pm 1074,81$ & $5016,8 \pm 959,44$ & $-4,37$ \\
\hline $\mathrm{KI}, \%$ & $-18,92 \pm 20,05$ & $-0,1 \pm 11,52$ & 99,47 \\
\hline
\end{tabular}

Note: * - significance of differences inp $<0,05$.

In elderly people, a walk favorably affected the state of respiratory system. It led to an increase in respiratory minute volume and maximal pulmonary ventilation. Moreover, sate anxiety significantly decreased.

Table6. The influence of a walk in the park on the parameters of the respiratory system and the level of anxiety.

\begin{tabular}{|c|c|c|c|}
\hline \multirow{2}{*}{ Parameters } & Initial value & After walk & \multirow{2}{*}{$\Delta \%$} \\
\cline { 2 - 3 } & $\mathrm{M} \pm \sigma$ & $\mathrm{M} \pm \sigma$ & \\
\hline State anxiety & $36,89 \pm 5,33$ & $29,66 \pm 6,11$ & $-19,59^{*}$ \\
\hline Trait anxiety & $32,14 \pm 9,65$ & $33,97 \pm 10,23$ & 5,69 \\
\hline RR & $14,91 \pm 7,88$ & $18,63 \pm 9,35$ & 24,95 \\
\hline RMV & $7,61 \pm 3,22$ & $9,78 \pm 6,45$ & 28,51 \\
\hline MPV & $49,11 \pm 15,74$ & $54,13 \pm 15,85$ & 10,22 \\
\hline
\end{tabular}

Note: * - significance of differences inp $<0,05$

To sum it up we can say, that being in the recreation area has a positive effect on the functional status of both elderly and young people. However, taking into consideration the fact that the initial parameters of the cardiorespiratory system of young people were within normal limits, changes in the physiological state of this group of people were insignificant compared to elderly people.

\section{Conclusions}

1. The improvement in cognitive functions is observed after a walk in the park. The capacity of visual and auditory memory, the speed of information processing and attention span have increased, but the number of mistakes has decreased. In addition, it reduces the level of state anxiety.

2. Favorable changes occur in the cardiorespiratory system due to staying in recreation areas. It decreases blood pressure and heart rate, but increases respiratory minute volume and maximal pulmonary ventilation.

3. The experiment helped to discover the age peculiarities of the influence of the recreation areas environment on the functional state of a person. The most marked positive dynamics of studied parameters is observed in people with maximum deviation from the normal values.

4. We can recommend elderly people walks in recreation areas as a drug-free way to enhance body functions.

\section{References}

1. E. Boman, I. Enmarker, S. Hygge, Noise Health, 7, 27 (2005) 
2. D. Guoqing, L. Guangxiang, X. Yaqian, K. Hakbong, Environ Sci Pollut Res Int, 26, 21 (2019)

3. E. Bahonar, T. N. Ghezeljeh, H. Haghani, J Complement Integr Med. 16, 3 (2019)

4. T. N. Ghezeljeh, M. Nasari, H. Haghani, H. R. Loieh, Complement Ther Clin Pract, 29, 147-152 (2017)

5. V. Saadatmand, N. Rejeh, M. Heravi-Karimooi, et. al., Int J Nurs Stud, 50,7, 895-904 (2013)

6. H. Jo, Ch. Song, H. Ikei, S. Enomoto, H. Kobayashi, Y. Miyazaki, Int J Environ Res Public Health. 16, 15 (2019)

7. Ch. Song, H. Ikei, Y. Miyazaki, Int J Environ Res Public Health, 15, 2 (2018)

8. K. Akarsu, A. Koç, N. Ertuğ, Eur J Cardiovasc Nurs, 18, 8 (2019)

9. S. Van Hedger, H. Nusbaum, L. Clohisy [et al.], Psychon Bull Rev, 26, 2, 522-530 (2019) 